\title{
Competencias de la curia diocesana en el ámbito de la creación, registro y certificación de las personas jurídicas en Colombia*
}

\author{
Competences of the Diocesan Curia in the Field of the Creation, Record and Certification of Legal Persons in \\ Colombia
}

Jorge Luis Miranda Pérez ${ }^{\text {a }}$

Pontificia Universidad Javeriana, Colombia

jorgeluismp611@hotmail.com

DOI: https://doi.org/10.11144/Javeriana.ucan35-51.ccda

Recibido: 14 Junio 2018

Aceptado: 16 Julio 2018

Publicado: 30 Diciembre 2018

\section{Resumen:}

Este artículo busca establecer, a través del análisis, la competencia que le ha sido otorgada a la curia diocesana entendida como cuerpo jurídico eclesiástico. A los clérigos se les ha designado el ejercicio de potestad sobre ciertos vínculos jurídicos que solo les compete a ellos mantener por su misma condición clerical. La potestad jurídica de la Iglesia para actuar dentro de sus mismos intereses ha sido permitida por el Estado colombiano, institución en la que el derecho divino converge con el derecho positivo, lo que permite salvaguardar los bienes de la Iglesia católica como institución divina al servicio del bien común.

Palabras clave: potestad eclesiástica, territorio diocesano, capacidad jurídica, persona jurídica, concordato.

\begin{abstract}
:
This article aims to ascertain, based on the analysis, the competence conferred on the diocesan curia, understanding it as an ecclesiastic legal body. Clergymen have been appointed to exercise the ecclesiastic power concerning some legal links that only they are competent to manage based on their clerical status. The legal power of The Church for acting on its own interest has been authorized by the Colombian State, which is the institution where the divine right converges with the positive right, and this allows safeguarding The Catholic Church's properties as a divine institution serving the common wellbeing.
\end{abstract}

Keywords: ecclesiastic power, diocesan territory, legal capacity, legal person, Concordat.

\section{Etimología canónica sobre el concepto de persona jurídica}

En los marcos generales del derecho, se estima que el término para referirse a la persona es remotamente antiguo: "Desde el derecho romano encontramos que se hablaba de ius, quod ad personas pertient para indicar el derecho referido a la condición de los seres humanos" (Lo Castro, 1996). Desde la concepción jurídica, dicho término ha logrado trasladarse a nuestra época y a otros centros de imputación de efectos jurídicos, distinto de los hombres que se encaminan a la conformación de las personerías jurídicas, pero conforme a los ejes de los fenómenos jurídicos.

Los doctrinantes del derecho canónico coinciden en aceptar la teoría mixta o intermedia, la cual es conocida también como teoría jurídica; aquí se entiende como persona jurídica a aquella "que consiste en la unión efectiva de las personas físicas que en toda persona moral intervienen, ya como constitutivas de ella, ya como destinatarias" (Mejía Aranzazu, 1953, p. 348).

Con relación a la llamada persona moral o jurídica cabe agregar que se la estima como una unidad jurídica instituida debidamente por una autoridad pública, con capacidad de alcanzar y ejecutar sus derechos. Las personas morales son consideradas como menores, lo que las hace gozar del beneficio de la restitutio in integrum, razón por la cual tienen el beneficio de reparación ante un perjuicio que se le llegara a generar.

Notas de autor

a Autor de correspondencia. Correo electrónico: jorgeluismp611@hotmail.com 
La capacidad jurídica de la persona para ejercer y gozar de derechos es congruente con el concepto jurídico que se ha desarrollado sobre la personalidad jurídica. Por otra parte, lo relacionado con el concepto de capacidad jurídica se refiere a que el hombre, por derecho consuetudinario, trae en su arraigo la aptitud para ser sujeto de derecho; esta condición lo hace dueño implícito de toda capacidad jurídica, sin necesidad de cambiarle su moldura natural.

Dentro del mismo orden de ideas, es relevante anotar que el concepto de capacidad jurídica surge como una necesidad imperante de protección para establecer igualdad de derecho y bajo el entendido de la reivindicación histórica que va en pro de la dignidad del hombre.

En general, las personas jurídicas en la Iglesia están conformadas por un conjunto de personas o masas de bienes. A aquellas personas jurídicas que se constituyen mediante un conjunto de personas se las denomina corporaciones, entre tanto, a las conformadas por un conjunto de bienes se las llama fundaciones.

Se denominarán personas jurídicas públicas a aquellas constituidas por la autoridad eclesiástica; por el contrario, cuando se lleguen a constituir mediante los entes particulares, recibirán la denominación de personas jurídicas privadas. Es preciso señalar que para la aprobación de una persona jurídica se debe surtir la aprobación de sus estatutos por medio de la autoridad competente (Le Tourneau, 2001).

\section{Reconocimiento de la personalidad jurídica eclesiástica}

Las consideraciones referentes a la personalidad jurídica parten del orden jurídico propiamente, el cual requiere de ciertos requisitos que le permiten desempeño y reconocimiento legal.

Conexo al cumplimiento de abordar todos los requisitos legales, es preciso indicar que

todo hombre debe tener acceso a la personalidad jurídica en cualquier tipo de ordenamiento, por lo mismo que, radicalmente, posee un derecho natural (anterior a cualquier ordenamiento) a asociarse con otros hombres en cualquier tipo de sociedad, en orden a conseguir su perfección personal integral (se ve, por tanto, la injusticia del derecho romano al no reconocer "personalidad" a los esclavos). Sin embargo, aunque el hombre (el "ser racional") es, de suyo, el sujeto inmediato y directo del derecho, ocurre a veces que la complejidad de relaciones que lleva consigo la vida social [hace] que [a] determinadas "organizaciones colectivas" se les dote de derechos y obligaciones independientemente de las personas (hombres) que componen esta organización. (Vera, 1990)

\section{Personería jurídica de la Iglesia en el derecho internacional}

La personalidad de la Santa Sede parte del mismo derecho internacional, por lo que tiene principios del derecho natural, como las reglas positivas propias de la práctica consuetudinaria y los artículos de los tratados afines a los miembros que hacen parte de la comunidad internacional, lo que determina los derechos y deberes de los miembros en sus relaciones. Desde el ámbito internacional, y referente al concepto de personas y personalidad jurídica, se hace necesario estimar que la personalidad internacional es la capacidad para ser sujeto activo y pasivo en la relación jurídico-internacional.

Desde el punto de vista de la doctrina iusnaturalista, todos aquellos entes que gozan de soberanía son llamados sujetos nativos del derecho internacional. Así, para que se dé una aceptación práctica de esa realidad, corresponde al derecho positivo internacional exigir el reconocimiento de esa condición básica, estipulada por el mismo ordenamiento y por los mismos miembros de la comunidad internacional. Dicho reconocimiento se hace manifiesto en declaraciones expresas solemnes mediante los documentos pertinentes; aquí también se incluye el reconocimiento implícito en los determinados hechos admisibles conforme a los atributos enmarcados en la personalidad internacional.

Igualmente, la Iglesia católica, como sujeto de derecho internacional, es un cuerpo atípico que, por su finalidad y naturaleza, no se puede identificar con las mismas políticas que constituyen a un Estado o a 
cualquier otro sujeto de derecho internacional; sin embargo, "bajo el aspecto social, no es difícil encontrar cierta analogía entre la estructura básica del Estado y la de la Iglesia” (Prigione, 1986, p. 110).

\section{La curia diocesana en la función administrativa}

La Iglesia particular, por naturaleza, es la diócesis, considerada una porción del Pueblo de Dios, y está bajo el cuidado pastoral del obispo exclusivamente (Instituto Martín de Azpilcueta, Código de Derecho Canónico [CIC], 369). La actividad del obispo es estrictamente personal y no colegial, pues la potestad suprema la ejerce el Romano Pontífice. El diocesano tiene la facultad de ejercer poder dentro de la jurisdicción de su Iglesia particular por la misma gracia que le otorga ser miembro del centro de poder de la Iglesia universal, "dado que la parte no puede actuar diferenciadamente ni en contraposición con el todo al que ontológicamente pertenece, se le subordina" (Barra, 2012, pp. 207-209).

Relacionado con la causa expuesta en el Concilio Vaticano II (decreto Christus Dominus, n.. 19), no resulta ajena al tema la celebración entre el Estado y las iglesias particulares - especialmente con las conferencias episcopales-, donde los ordenamientos locales les reconocen personalidad jurídica propia.

En relación con los actos sobre la administración de la curia diocesana, cabe anotar que el diocesano no puede abarcar personalmente todas las funciones que le competen sin descuidar en su totalidad el ministerio. Para el cumplimiento de su ardua misión el diocesano requiere, obligatoriamente, del apoyo del colegio de consultores, del consejo de asuntos económicos y del ecónomo, quienes conservan las funciones propias que demanda el derecho universal.

La tarea de estos profesionales se hace indispensable ya que estas no pueden ser desarrolladas por el obispo diocesano; así mismo, la responsabilidad del diocesano es exclusiva, es él quien debe acatar la función propia de su cargo como administrador de los bienes de la diócesis.

Dentro de la representatividad de la Iglesia, el obispo es la autoridad principal en la diócesis; así, el obispo y su presbiterio conforman en conjunto un equipo de trabajo; no obstante, el obispo es quien, al final, toma las decisiones definitivas. Por tanto, conviene al obispo ejercer las riendas en los servicios que ofrece esta porción del Pueblo de Dios, sin escatimar también en los oficios que requieren de atención, como el ejercicio de la potestad legislativa en su Iglesia particular, que tiene el interés de proteger los derechos de las personas y de preservar el bien común, en general, de la comunidad que legisla.

\section{Canonización de la ley civil}

A la luz del canon 22, y consecuente a las leyes civiles consignadas por el derecho de la Iglesia, es pertinente resaltar que estas leyes deben converger en los efectos del derecho canónico sin ser contrarias al derecho divino, para que así haya congruencia y no se disponga otra cosa en el derecho canónico.

Dentro de la anterior posición, García Martín (2006) destaca que el término canonización apunta a la remisión del derecho canónico a las leyes civiles, más exactamente sobre la aceptación de las leyes civiles en el ordenamiento canónico. El canon 3 versa sobre las disposiciones de mantener lo establecido por la Santa Sede en la legislación canónica aun cuando se contraigan convenios con las naciones o con otras sociedades políticas. A tal apreciación se le suman la pertenencia y el papel del fiel inmerso tanto en la comunidad civil como en la Iglesia; esta situación conlleva al sometimiento de dos ordenamientos debidamente coetáneos.

Los ordenamientos jurídicos de los diferentes Estados no son iguales, así como las normas por las cuales se rigen estos Estados difieren de un territorio a otro, lo que genera que esas diferencias no logren consignarse en el código; sin embargo, dicha limitación permite la remisión a los ordenamientos legislativos de los Estados. 


\section{Las personas jurídicas en el derecho civil}

El concepto de persona o de personalidad es una categoría estrictamente jurídica, uno de los arbitrios de la técnica jurídica para incluir en el derecho al ser humano, a un conjunto de seres humanos o a un conjunto de bienes y convertirlos en titulares de derechos y obligaciones (Valencia, 2003).

Conforme a lo que dispone la Constitución Política, "toda persona tiene derecho al reconocimiento de su personalidad jurídica" (art. 14). Aunque el reconocimiento de dar vida y de revestir de derechos y obligaciones a la personalidad jurídica quedó consagrado en la Carta Magna, el constituyente de 1991 quedó ambiguo en lo referente a la protección de tales derechos, pues no abarcó dicha protección como derecho fundamental; así fue como los aspectos con los que se atavía la personalidad jurídica quedaron a consideración de la doctrina y la jurisprudencia.

\section{Creación de las personerías jurídicas eclesiásticas}

En atención al artículo 4 del Concordato y al 24 de la ley 57 de 1887, podemos extraer que las iglesias y las asociaciones religiosas católicas contemplan una personería jurídica ipso iure, lo cual significa que no necesitan de un reconocimiento expreso.

Constituir una persona jurídica implica más que un acto jurídico por parte de la autoridad que se reviste de la facultad especial sobre la existencia del ente jurídico; en efecto, la personalidad no solo corresponde a un instrumento del que puede hacer uso el legislador eclesiástico por razones de intereses prácticos, de organización o control, entre otros. Se estima, a modo de añadidura y con relación a la participación de la personalidad en la Iglesia, que el concepto de erección corresponde al acto jurídico por el cual una asociación, guarnecida de los oportunos iura et privilegia, se constituye estrictamente en persona jurídica.

La persona jurídica se hace poseedora de una existencia jurídica que le causa independencia respecto a los miembros integrantes, emanándose marcadas implicaciones en el ámbito canónico que causan la concepción de la persona jurídica como un ente directamente participativo que define el fin público señalado por la Iglesia. La erección sitúa a la persona jurídica en un escenario de rigor público, oficial, en el que la autoridad eclesiástica se compromete como parte de su propio régimen.

\section{Representantes legítimos de las personas jurídicas}

La persona jurídica debe efectuar sus actuaciones a través de sus legítimos representantes; así, en el caso de la persona jurídica pública expresamente, actuarán como legítimos representantes aquellos a quienes el derecho universal o particular les reconozca la representación o les brinden o estipulen los propios estatutos. Para el caso de la persona jurídica privada, surtirá efectos de competencia a quienes por medio de los estatutos se les haga atribuible la competencia requerida (Instituto Martín de Azpilcueta, CIC, 118; Vera, 1990).

\section{Del registro de la personería jurídica eclesiástica}

Recordemos expresamente que a las designadas personas jurídicas de derecho público eclesiástico, del cual trata el referido artículo, también corresponden las erigidas, como la Conferencia Episcopal de Colombia, la Conferencia de Superiores Mayores Religiosos, las diócesis y las demás circunscripciones eclesiásticas que les sean asimilables a estas en el derecho canónico, como las arquidiócesis, el ordinariato castrense, las prelaturas, los vicariatos apostólicos, las prefecturas apostólicas y las abadías, los seminarios mayores, las parroquias y 
demás comunidades religiosas, como los institutos religiosos, los institutos seculares y las sociedades de vida apostólica tanto de derecho pontificio como diocesano (Secretaría Distrital de Hacienda, 2006).

De igual forma, el artículo en mención reconoce que, a su vez, gozarán de igual reconocimiento "las entidades eclesiásticas que hayan recibido personería jurídica por un acto de la legítima autoridad, de conformidad con las leyes canónicas. Para que sea efectivo el reconocimiento civil de estas últimas, basta que acrediten con certificación su existencia económica” (Secretaría Distrital de Hacienda, 2006).

\section{Relación histórica entre la Iglesia católica y el Estado colombiano}

Desde los contextos históricos de América Latina, en los que se empiezan a forjar las distintas luchas de poder de los gobiernos, Colombia no es la excepción en querer fundamentar sus asentamientos de poder a través de sus partidos políticos. En los albores del siglo XIX se verifica que la Iglesia católica se encontraba establecida en amplias comarcas geográficas, con mayor prevalencia en los territorios de la cordillera oriental, en las regiones propiamente de Bogotá, Tunja y Pamplona, extendiéndose, a su vez, a Popayán, Pasto y el noroccidente antioqueño.

\section{Reconocimiento de independencia y autonomía de la Iglesia católica respecto a las normas civiles colombianas}

A partir del comunicado del Comité Permanente de la Conferencia Episcopal de Colombia, publicado en la misma fecha en la cual se registró formalmente la firma del nuevo acuerdo concordatario, se esgrime en presentar a la Iglesia en dicho concordato como un espíritu que se funge en las bases de la mentalidad conciliar.

\section{Reconocer la competencia otorgada a la diócesis en la creación, registro y certificación para otorgar personería jurídica eclesiástica}

Desde el contexto eclesiástico, existe una realidad reconocida como Sagrada Tradición, que consiste en la predicación apostólica, mantenida en el tiempo y adjudicada a los obispos, de cuyo origen se remite a los apóstoles, por lo que se mantiene desde entonces su progreso en la Iglesia con asistencia del Espíritu Santo.

Cuando los obispos hacen proclamación de esta Sagrada Tradición son revestidos del carisma de la verdad. Como lo contempla el canon 375, por única instauración divina, los obispos suceden a los apóstoles, con excepción del Papa, que sucede a un apóstol con nombre propio, como san Pedro. La raíz de la palabra obispo surge del griego y del latín episcopus, cuyo significado corresponde a guardián, vigilante o inspector; en relación a ello, es significativo anotar que la palabra diócesis tiene su nacimiento en la cultura romana, puesto que estas correspondían a las divisiones administrativas durante el florecimiento del imperio romano.

El obispo tiene las siguientes potestades:

- Potestad legislativa: el obispo tiene la potestad, en su diócesis, de aprobar las leyes que considere sean pertinentes al bien general. De igual forma, tiene la disposición de prohibir aquello que la ley común no permita o de, en tal caso, consentir lo que no sea contrario a esta ley común.

- Potestad ejecutiva: el obispo tiene la facultad de administrar a cabalidad la propiedad eclesiástica, para ejercer en totalidad su dirección. Igualmente, en lo que se refiere a la enajenación de los bienes eclesiásticos, no se permite enajenar ningún bien sin el consentimiento expreso del obispo. De acuerdo con lo descrito por el canon 393, "el obispo representa a la diócesis en todos los negocios jurídicos de la misma”. 
- Potestad judicial: es preciso proyectar esta potestad desde dos puntos: por un lado la extrajudicial, referida a la facultad que le atañe al ejercicio de un poder judicial dentro de un proceso canónico, bien sea público o en conciencia, y por otro, la propiamente judicial, que manifiesta el poder judicial del obispo en el ejercicio ante cualquier proceso canónico. Esta última es relevante al momento de actuar como juez de primera instancia en los juicios del Tribunal Eclesiástico (Vargas Holgín, 2015).

Los elementos jurídicos eclesiásticos dotan de todo el sustento legal a la diócesis para los fines hasta ahora descritos. Por su parte, la ley civil ha facultado a la Iglesia católica para ejercer la independencia a través del derecho canónico en el manejo de sus bienes al servicio de la fe y la práctica de los propósitos por la cual fue erigida.

Este pueblo santo y vigilado por el Espíritu se unifica en los dones del servicio, los cuales son vigilados por la autoridad eclesiástica, a la que el mismo Espíritu escoge para preservar los dones de la fe; dentro de este mismo contexto encontramos el oficio profético encaminado a la misión apostólica.

En general, las leyes fueron creadas para corregir comportamientos contrarios no solo a la sana convivencia, sino al buen vivir del bien común, para corregir conductas no solo inapropiadas, sino elevadas al rango de establecer los límites de salvaguardar los derechos y deberes de toda la comunidad.

La Iglesia católica es una comunidad organizada y erigida en los principios de Cristo, y para el cabal funcionamiento de toda organización se requiere de parámetros jerárquicos que permitan establecer orden y control en el funcionamiento de sus actividades. Bajo esta apreciación, nace el régimen de potestad, que inculca el hacer las cosas con orden y con autonomía, en aras de salvaguardar los propios intereses de este cuerpo consagrado en la fe.

De acuerdo con esto, para ejercer el fenómeno de la potestad, se requiere de personal calificado, para ser más exacto, de la diócesis y el obispo. El obispo delega las funciones propias de la misión apostólica y, en conjunto con sus colaboradores, dirige y organiza las funciones administrativas de su diócesis.

Con base en lo relatado hasta ahora, podemos concluir que todas las manifestaciones descritas convergen hacía el nacimiento de los oficios eclesiásticos y se encuentran bajo el mismo ideal de conservar los preceptos divinos con la propia autoridad clerical que les han sido delegados.

\section{Referencias}

Barra, C. R. (2012). Derecho público canónico. Buenos Aires: Marcial Pons Argentina.

García Martín, J. (2006). Normas generales del código de derecho canónico (1.. edición). Valencia: Editorial Cultural y Espiritual Popular (Edicep). Recuperado de https://es.scribd.com/document/398009172/GARCIA-MARTI N-J-Normas-Generales-Del-Codigo-de-Derecho-Canonico-Sf

Instituto Martín de Azpilcueta (ed.). (2007). Código de Derecho Canónico. Pamplona: Ediciones Universidad de Navarra (Eunsa).

Le Tourneau, D. (2001). El Derecho de la Iglesia (5.. edición). Madrid: Rialp.

Lo Castro, G. (1996). De las personas físicas y jurídicas. En Instituto Martín de Azpilcueta (ed.), Comentario exegético al Código de Derecho Canónico. Pamplona: Ediciones Universidad de Navarra (Eunsa).

Mejía Aranzazu. F. (1953). La iglesia como persona jurídica de derecho interno. Revista Pontificia Universidad Bolivariana, 18(68), 346-360. Recuperado de https://revistas.upb.edu.co/index.php/upb/article/view/3806/3 395

Prigione, J. (1986). La Iglesia como persona de derecho de gentes. Personalidad internacional de la Santa Sede: la cuestion romana y el Estado de la Ciudad del Vaticano. Jurídica, 18. Recuperado de https://revistas-colaboracio n.juridicas.unam.mx/index.php/juridica/article/view/11052/10105

Secretaría Distrital de Hacienda. (2006). Memorando n.. 982347912837. Concepo 1143. Recuperado de https://ww w.alcaldiabogota.gov.co/sisjur/normas/Norma1.jpp?i=22020 
Valencia, R. H. (2003). Las tres grandes teorias generales del derecho (3.. edición). Medellín: Señal Editora.

Vargas Holgín, H. (2015). ¿Qué son los obispos, cuál es su función? Pabloeze.wordpress.com. Recuperado de https://p abloeze.wordpress.com/2015/10/24/que-son-los-obispos-cual-es-su-funcion

Vera, U. F. (1990). Derecho Eclesiástico I. Madrid: Tecnos.

\section{Notas}

* Artículo de investigación

\section{Licencia Creative Commons CC BY 4.0}

Cómo citar este artículo: Miranda Pérez, J. L. (2018). Competencias de la curia diocesana en el ámbito de la creación, registro y certificación de las personas jurídicas en Colombia. Universitas Canónica, 35(51). https://doi.org/10.11144/Javeriana.ucan35-51.ccda 